\title{
An Estimate of the 2016 Census Figures Of the Population of Nigeria Using a Modified Discrete Malthusian Model
}

\author{
${ }^{1}$ Richard A.Kimbir, ${ }^{2}$ James M.Chin* \\ Department of Mathematics/Statistics/Computer Science University of Agriculture Makurdi \\ PMB 2373, Makurdi, Nigeria
}

\begin{abstract}
Census is the procedure of systematically acquiring and recording information about the members of a given population. It is a regularly occurring and official count of a particular population. In this paper, we considered only the modified time discrete Malthusian model as the discrete time Malthusian model could not be amenable to the given data. We modified the growth model by Thomas Robert Malthus by fitting a straight line through a given growth rate data. The later is applied at any point in time unlike the former where emphasis is made on equal time intervals (per decade) of conducting census. The numerical simulation carried out shows that the estimated population are higher than the actual census figure apart from the data recorded in 1963 and 1973. Our findings indicates a non constant population growth rate as result of human and environmental factors . Using our model all Nigerians are hopefully of achieving an estimated population of 220.55865 million in 2016.
\end{abstract}

Keywords: Census, modified model, growth rate, fitting a straight line, estimated population

\section{Introduction}

The word "census" comes from the Latin verb 'Censere', which means - contrary to what's expected not 'to count' but rather 'to assess', or in a term closer to the world of statistics, 'to estimate'. Population census is a complete process of collection, reception, assessment, analysis, publication and distribution of demographic, economic and social data, which relate, at a given moment in time, to all the residents of a country or of a welldefined partial geographic area; as reflected in the Population and Housing Censuses Handbook of the UN, 1992. (Centre for Bureau of statistics, state of Israel, 2014)

The practice of census taking is an old tradition as dated back during the time of the Israel under the leadership of Moses in the wilderness of Sinai (Holy Bible, Number 26: 1-64); The holy Bible also mentioned the census made by King David in about 100BC.

Population Estimates is the calculated number of people living in an area as of a specified point in time. The estimated population is calculated using a component of change model that incorporates information on natural increase (births, deaths) and net migration (net domestic migration, net international migration) that has occurred in an area since the latest decennial census.

Every country needs an accurate and accepted census data to plan for virtually everything. Effort to actualize this is met with a lot of difficulties vobi, (2000), has this to say, "you must resist and stay away from anything called census. Biafra foundation in collaboration with MASSOB (Moment for the Actualization of the Sovereign State of Biafra) and other Biafra organizations demand that you boycott this census". These were words of pressure group in Nigerian calling for a boycott of the 2006 census exercise. Instead of mobilizing people for effective census, some groups in the country decided not to participate in the national census and the end result is under counting and inaccurate result. Tom (2006), "Population census has remained the most sensitive and most controversial in the politics and administration of Nigeria". Such controversies sometimes led to misunderstanding between ethnic groups in the country. Most of the problems we have in Nigeria arise from population problem. Our country has laid so much emphasis on population and it has become difficult to ascertain the actual figures of the population of the country. Mohammed. (2006), despite superior statistical techniques, effective administration increased funding, the quality of census exercise continue to deteriorate mainly because of the political problem associated with its conduct. The conduct of population census in Nigerian is characterized by ethnicity and manipulations; each group tries to manipulate to have more figures, therefore it become difficult to have an accurate census. Population association of Nigeria PAN (1990), "Gradually, from 1952 onwards, the people became aware that political power arising from the number of elected number of parliament or local councils as well as the allocation of government amenities depend largely on the size of population with this awareness, it has become imperatively difficult to have the true census figures of the population of Nigeria. "Population association of Nigeria PAN (1990), "The census count thus became political rather than a statistical exercise -----"

There are problems associated with conduct of national census in Nigeria, this ranges from transport, lack of adequate preparation, communication, lack of proper awareness of the importance of head count. 
Conduction of census has a greater role in our society especially in state creation, sharing of federal allocation, allocation of seats at the national assembly and establishment of social amenities like schools, hospitals etc.

History has made it clear that in 1866, Nigeria had their first census conducted by the British colonialist in the then Lagos colony (Tom, 206), and later in both northern and southern protectorates in the year 1914.

Bamgbose (2009) . In their paper title falsification of population census data in a heterogamous Nigeria states has this to say, for an accurate population census in Nigeria, population census figures should not be used for allocation of governmental benefits. A related study was conducted by Anthony and Agoyi (2011), in their work titled, A biometrics approach to population census and national identification in Nigeria: a prerequisite for planning and development said, a biometric system of data collected and a centralised data base is the key in solving the Nigerian census problem. A similar study was conducted by Augustus (2012), to study Uganda population growth. The result of their analysis shows that the approximated population growth rate compares well with statistically predicted values in literature.

According to Isiaka et al. (1997) "Some Nigerian scholars believed that there is no any Nigerian who can be fair or seem to be fair in the conduct of census". The tension and controversies often generated by its result reinforced the question of ethnic domination and mutual suspicion among the various ethnic groups in the country.

The discrete Malthusian model estimate population at discrete time interval, but in 1941 census was not conducted in Nigeria because of the world war II, and this makes the model in effective, since $\mathrm{n}$ is an integral value and some values are missing. Therefore it cannot be applied. In view of the above, we present the improved Malthusian growth model that used a time dependent growth rate, which is acquired by fitting a straight line through a given growth rate data using the least square regression lines.

The rest of the paper will be organized as follows. We provide the mathematical model in section II while the application in section III, analysis of the results are provided in section IV and we draw conclusions in section $\mathrm{V}$

\section{The Mathematical Model}

The discrete Malthusian growth model is named after an English social scientist Thomas Robert Malthus who leaves between (1766-1834). It is a special example of discrete dynamic system or difference equations. The model state that; the population in the next decade is equal to the current population plus the current population times the average growth rate $(\varepsilon)$ of the population. The model begins with some starting population say $\mathrm{p}_{0}$, then future population are predicted at each decade (discrete time interval). By starting with this initial given population $\left(\mathrm{p}_{0}\right)$, then finding the next population by multiplying $(1+\varepsilon)$. This gives a sequence of predicted population based solely on the population from the preceding decade.

The discrete Malthusian model states that, the population of the next generation is simply proportional to the population in current generation.

Let $p(t)$ denote the size of the population at time $t$.

Let $\beta(t)$ be the number of birth at time $t$

Let $\mu(\mathrm{t})$ denote the number of death at time $t$

Then the discrete Malthusian Growth model is

$\mathrm{p}_{\mathrm{n}+1}=(1+\varepsilon) \mathrm{p}_{\mathrm{n}}$

Where $\varepsilon$ is the difference between birth and death $(\beta-\mu)$ and is called the population growth rate

\subsection{Modified Malthusian Growth Model}

In this section will present the improved Malthusian growth model that used a time dependent growth rate, which is acquired by fitting a straight line through a given rate data.

Here the generalized discrete dynamic growth model is given by

$\mathrm{p}_{\mathrm{n}+1}=\mathrm{f}\left(\mathrm{p}_{\mathrm{n}}\right)$

The growth rate for the model is computed by dividing the population at one census date by the population at the previous census date and subtracting one from the result. When the average is taken over all the census date, we found the average growth rate $\varepsilon_{0}$, this result in the discrete Malthusian growth model.

$\mathrm{p}_{\mathrm{n}+1}=\varepsilon_{0} \mathrm{p}_{\mathrm{n}}$

A modified time dependent growth rate can be found by fitting a line through the given data. The best fit to this growth rate date is then found.

If we denote this by $k(n)$ where $n$ is the date of the census, then the resulting difference equation is given by

$\dot{p}_{n+1}=[1+k(n)] p_{n}$ 


\section{Application}

We shall use equation (2.1.2) to estimate the population of Nigeria in the 2016 census. The census data for the history of Nigeria is presented in table 4.2

\subsection{Application Using Malthusian Growth Model}

The model equation is

$$
\mathrm{p}_{\mathrm{n}+1}=(1+\varepsilon) \mathrm{p}_{\mathrm{n}}
$$

This model estimate population at discrete time interval, but in 1941 census was not conducted in Nigeria because of the world war II, and this makes the model ineffective, since $\mathrm{n}$ is an integral value and some values are missing. Therefore it cannot be applied.

\subsection{Application Using the Modified Malthusian Growth Model}

The line of best fit

The equation of the line is

$\varepsilon_{0}=\mathrm{a}_{0}+\mathrm{a}_{1} \mathrm{Y}$

Where $\varepsilon_{0}$ is the growth rate and $\mathrm{Y}$ is the time in years.

The normal equations are

$\sum \varepsilon_{0}=\mathrm{a}_{0} \mathrm{~N}+\mathrm{a}_{1} \sum \mathrm{Y}$

$\sum \mathrm{Y} \varepsilon_{0}=\mathrm{a}_{0} \sum \mathrm{Y}+\mathrm{a}_{1} \sum \mathrm{Y}^{2}$

Table 4.1 in the appendix shows how to find $\sum \varepsilon_{0}, \sum \mathrm{Y}, \sum \varepsilon_{0}{ }^{2}, \sum \mathrm{Y}^{2}$

If $\varepsilon_{0}$ is considered to be the dependent variable $Y$ is the independent variable. The equation of best fit is $\varepsilon_{0}=\mathrm{a}_{0}+\mathrm{a}_{1} \mathrm{Y}$ and the normal equations are

$\sum \varepsilon_{0}=a_{0} \mathrm{~N}+\mathrm{a}_{1} \sum \mathrm{Y}$

$\sum \mathrm{Y} \varepsilon_{0}=\mathrm{a}_{0} \sum \mathrm{Y}+\mathrm{a}_{1} \sum \mathrm{Y}^{2}$

Since there are 6 pairs of $Y$ and $\varepsilon_{0}$

$\mathrm{N}=6$, and the normal equations become

$2.532=6 \mathrm{a}_{0}+11817 \mathrm{a}_{1}$

$3660.63=11817 \mathrm{a}_{0}+58917185 \mathrm{a}_{1}$

Solving equation (3.2.2) and (3.2.3) simultaneously

We have

$\mathrm{a}_{1}=0.000098568$ and

$\mathrm{a}_{0}=0.22786$

Hence the equation (3.2.1) becomes

$\varepsilon_{0}=0.22786+0.000098568(\mathrm{Y})$

But $\varepsilon_{0}=\mathrm{K}(\mathrm{n})$ and $\alpha=\mathrm{Y}$

Therefore

$\mathrm{K}(\mathrm{n})=0.22786+0.000098568 \alpha$

Hence the modified equation is

$\mathrm{p}_{\mathrm{n}+1}=[1+(0.22786+0.000098568 \alpha)] \mathrm{p}_{\mathrm{n}}$

Psing equation (3.2.5) we estimated the census figures of the population of Nigeria, the result is sho (4.2)

\section{Analysis}

Refer to figure 4.2, we observed that the population increase from 1921 to 1931 is slow, however, there is a sharp increase from 1953 to 1973 . The sharp increase may be attributed to political reasons.

A critical observation of figure 4.3 (the estimated population graph using model (3.2.5) shows that the population increases as the time increases. This means that, population growth is directly proportional to time. This is in agreement with the Malthusian theorem of population. In figure 4.3 we tried to compare the census data curve and the estimated data curve. A critical analysis shows that at the beginning (i.e $\alpha_{0}=1921, \alpha_{1}=$ $\left.1931, \alpha_{2}=1953\right)$ the modified model over estimated the population. Between 1953 to $1991\left(\alpha_{2}=1953, \alpha_{5}=\right.$ 1973) the model under estimated the population. This sharp change could be attributed to manipulations by politicians. After $1973\left(\alpha_{4}=1973\right)$ we observed that the graph rises steadily above the census data curve to 2016.

\section{Conclusions}

We conclude that the 2016 estimated census figures of the population of Nigeria using the modified discreet Malthusian model could be 220.55865 million. 


\section{References:}

[1]. Anthony ,T. E. And Agoyi, M. (2011) . A Biometrics Approach to Population Census and National Identification in Nigeria: A Prerequisite for Planning and Development International Relations Department1, Computer Engineering Department2 Cyprus International University, Lefkosa, Mersin 10, Turkey1, 2 aeniayejuni@yahoo.com1, magoyi@ciu.edu.tr 2

[2]. Ajayi, B(2005) The Population and Nigeria data Contradictions. hptt.//.Nigerian world.com.

[3]. Bamgbose J .A., (2009) Falsification of population census data in aheterogeneous Nigerian state: The fourth republic example .Political Science Department Lagos State University, Lagos, Nigeria. E-mail: bamgboseja@yahoo.com.

[4]. Centre for bureau of statistics, state of Israel (2014)

[5]. Isiak, A. and Mannir, A.D.(1991). Breaking the myth; Shehu Musa and the 1991 census; Sepectrum books Limited.

[6]. Intervarsity Christian Fellowship of the United States of America,(1994)The NIV Quiet Time Bible; USA intervarsity Press.

[7]. Mohammed, H. (2006) the politics of Nigeria's head count.hptt.www.gamji.com/haruna / table/htm

[8]. Mahatty, J.M. (2003) Discrete Malthusian growth. San Diego state University USA. www.ohan sdsu. Edu /jmahaffy/course/sooa/math121

[9]. Pollard,A. H. et al. (1974) Demographic Techniques; Singapore; kyodo-shing.

[10]. Population Association (1990). Every body's guide to the Nigeria census, Ibadan ohiey

[11]. Tom, M. E.(2006). Nigeria census, the untold story, hptt $/ / \mathrm{www}$.daodu.com $/ \mathrm{mbekel} / \mathrm{htm}$

[12]. Vobi (2005). Nigeria census and other matters. hptt//.www.message board; biafranigeria.world.com

[13]. Walter,J.M.(1984). Concept of mathematical modelling McGraw.Hill, USA.

Table 4.1: Table shown how to find $\sum \varepsilon_{0}, \sum \mathrm{Y}, \sum \varepsilon_{0}{ }^{2}, \sum \mathrm{Y}^{2}$

\begin{tabular}{lllll}
\hline Time in years $(\mathrm{Y})$ & Rate $\left(\varepsilon_{0}\right)$ & $\mathrm{Y} \varepsilon_{0}$ & $\mathrm{Y}$ & $\varepsilon_{0}{ }^{2}$ \\
\hline 1931 & 0.064 & 123.58 & 3728761 & 0.0040 \\
1953 & 0.587 & 1146.41 & 3814209 & 0.3445 \\
1963 & 0.756 & 148.02 & 3853369 & 0.5715 \\
1973 & 0.437 & 862.20 & 3832729 & 0.1909 \\
1991 & 0.114 & 226.97 & 39664081 & 0.0129 \\
2006 & 0.574 & 1153.45 & 4024036 & 0.3306 \\
$\mathbf{1 1 8 1 7}$ & $\mathbf{2 . 5 3 2}$ & $\mathbf{3 6 6 0 . 6 3}$ & $\mathbf{5 8 9 1 7 1 8 5}$ & $\mathbf{1 . 4 5 4 4}$ \\
\hline
\end{tabular}

Table 4.2: The census data for Nigerian population

\begin{tabular}{|c|c|}
\hline $\begin{array}{l}\text { Time in } \\
\text { years }\end{array}$ & $\begin{array}{l}\text { Census data } \\
\text { (million) }\end{array}$ \\
\hline 1921 & 18.700 \\
\hline 1931 & 19.900 \\
\hline $1953^{-}$ & 31.600 \\
\hline $1963^{-}$ & $55.500^{\circ}$ \\
\hline $1973^{\circ}$ & 79.800 \\
\hline 1991 & $88.900^{\circ}$ \\
\hline 2006 & 140.004 \\
\hline
\end{tabular}

Table 4.3: The estimated population using equation (3.2.5)

\begin{tabular}{|c|c|}
\hline $\begin{array}{l}\text { Time in } \\
\text { years }\end{array}$ & Census \\
\hline & data(million) \\
\hline 1921 & 18.70000 \\
\hline $1931^{-}$ & 26.52024 \\
\hline $1953^{-}$ & 37.66837 \\
\hline 1963 & -53.539899 \\
\hline $1973^{-}$ & $76.15164^{-}$ \\
\hline 1991 & 108.44822 \\
\hline $2006^{-}$ & 154.60242 \\
\hline 2016 & 220.55865 \\
\hline
\end{tabular}

Table 4.4: The comparison of census data in table 4.1 with that of the modified model (equation 3.2.5)

\begin{tabular}{|c|c|c|}
\hline Time in years & Census Population(million) & $\begin{array}{l}\text { Model } \\
\text { predication(million) }\end{array}$ \\
\hline 1921 & 18.700 & 18.70000 \\
\hline $193 \mathrm{I}^{-}$ & 19.900 & 26.52024 \\
\hline 1953 & 31.600 & $37.66837^{-}$ \\
\hline $1963^{-}$ & $55.500^{-1}$ & 53.53989 \\
\hline $1973^{-1}$ & $79.800^{\circ}$ & $76.15164^{-}$ \\
\hline 1999'- & 88.900 & To8.448227" \\
\hline 2006 & 140.004 & 154.60242 \\
\hline 2016 & & 220.55865 \\
\hline
\end{tabular}

$$
\alpha_{0}=1921, \alpha_{1}=1931, \alpha_{2}=1953, \alpha_{3}=63 \text {, }
$$$$
\alpha_{4}=73, \alpha_{5}=1991, \alpha_{6}=2006, \alpha_{7}=2016
$$

$$
\begin{aligned}
& \alpha_{0}=1921, \alpha_{1}=1931, \alpha_{2}=1953, \\
& \alpha_{3}=6=73, \alpha_{5}=1991, \alpha_{6}=2006, \\
& \alpha_{7}=2016
\end{aligned}
$$

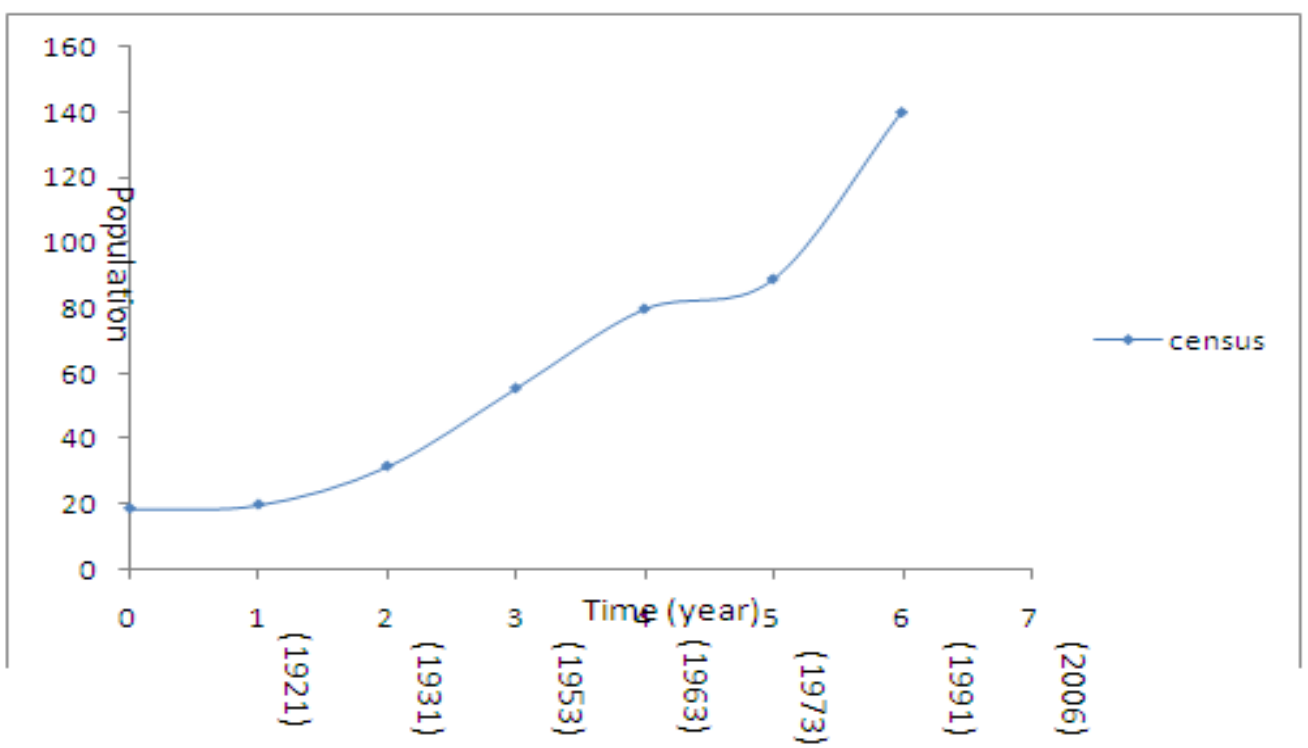

Figure 4.1 The graph of the Nigerian census data 


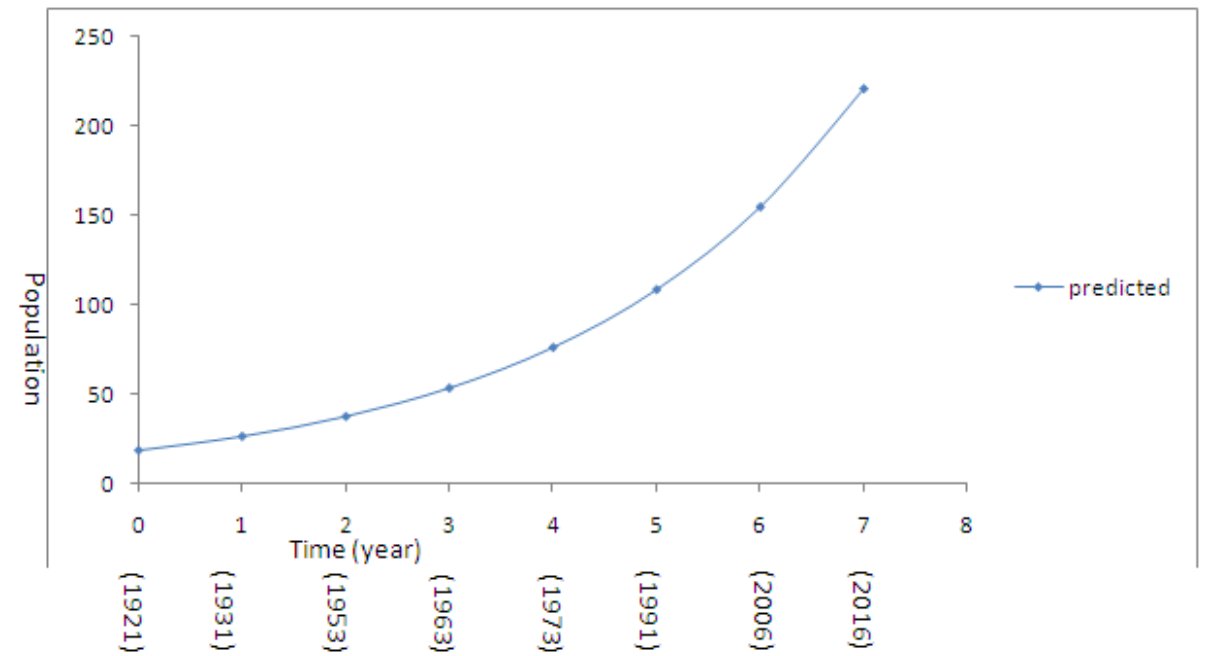

Figure 4.2 Graph of the estimated census data of the Nigerian population using the modified model

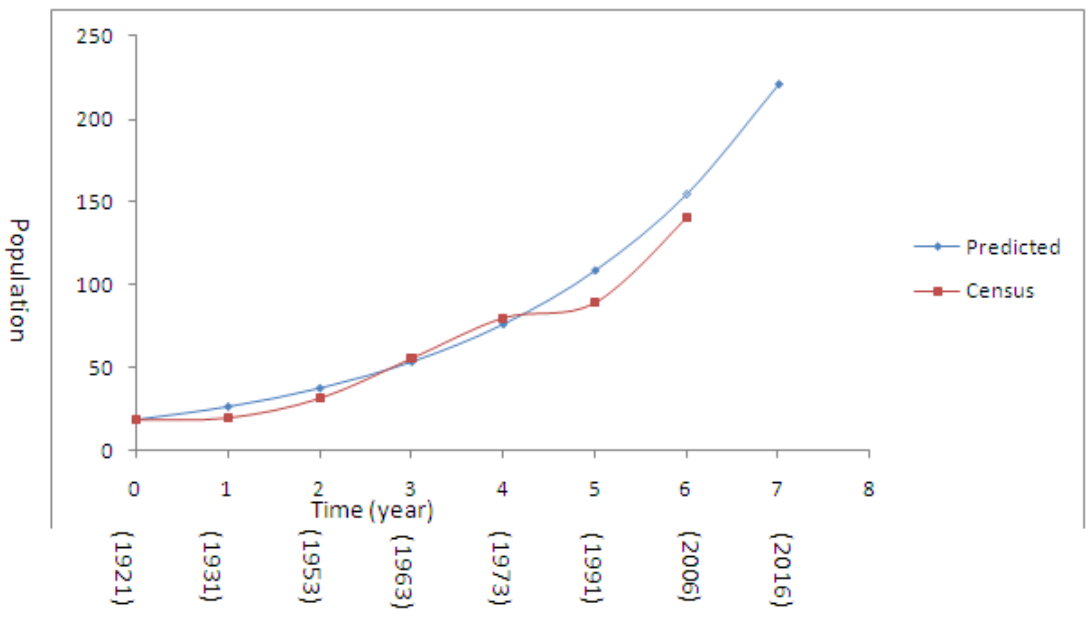

Figure 4.3: Graph of the census figures of Nigerian population and the estimated census figures of the population of Nigerian using the modified model

A computer program to help estimate the Nigerian census figures

Clear all

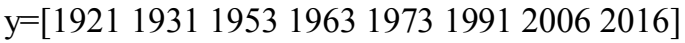

for $\mathrm{i}=1: 8$

$0+\mathrm{y}(\mathrm{i})$

$\operatorname{disp}\left(' y(i)^{\prime}\right)$

end

$\mathrm{p}(1)=18.70$

for $\mathrm{i}=1: 7$

$\mathrm{p}(\mathrm{i}+1)=(1+(0.3171+0.00003172 * \mathrm{y}(\mathrm{i}))) * \mathrm{p}(\mathrm{i})$

end 